\title{
ANALISIS PERUBAHAN TATA GUNA LAHAN TERHADAP DEBIT BANJIR SUB-SUB DAS KEYANG-SLAHUNG- TEMPURAN (KST)
}

\author{
M. Khuzaimy Rurroziq Basthoni ${ }^{1)}$, Gusfan Halik ${ }^{2)}$, Entin Hidayah ${ }^{3)}$ \\ Civil Engineering Department, Engineering Faculty, Jember University, \\ Jl. Kalimantan No 37, Kampus Tegalboto, Jember 68111, Indonesia \\ email: khuzaimybasthoni@gmail.com ${ }^{1)}$, gusfan.teknik@unej.ac.id ${ }^{2)}$, \\ entin.teknik@unej.ac.id ${ }^{3)}$
}

DOI: http://dx.doi.org/10.29103/tj.v10i2.309

(Received: June 2020 / Revised: August 2020 / Accepted: August 2020)

\begin{abstract}
Abstrak
Perubahan tata guna lahan mempengaruhi puncak debit banjir pada suatu DAS. Setiap tahunnya, Kota Ponorogo dilanda bencana banjir pada saat musim penghujan tiba. Penelitian ini bertujuan untuk menganalisis pengaruh perubahan tata guna lahan terhadap puncak debit banjir di sub-sub DAS Keyang-Slahung-Tempuran dengan menggunakan program bantu SWAT (Soil and Water Assessment Tool). Hasil penelitian menunjukan bahwa perubahan tata guna lahan berdampak pada peningkatan puncak debit banjir. Puncak debit banjir tertinggi terjadi pada tanggal 12 Maret 2018, dengan luas hutan $29,55 \%$ (tata guna lahan tahun 2015) menghasilkan puncak debit banjir $573,70 \mathrm{~m}^{3} / \mathrm{s}$. Pada waktu dan penggunaan data curah hujan yang sama, puncak debit banjir terendah terjadi saat luas hutan 31,07\% (tata guna lahan tahun 1990) yaitu $572,50 \mathrm{~m}^{3} / \mathrm{s}$. Berdasarkan kondisi existing tata guna lahan saat ini, masih terjadi banjir sehingga diperlukan skenario pola tata guna lahan. Skenario tiga merupakan pola tata guna lahan yang optimal, dengan luasan hutan $45,37 \%$ menghasilkan puncak debit banjir $563,50 \mathrm{~m}^{3} / \mathrm{s}$ (siaga normal).
\end{abstract}

Kata kunci: puncak debit banjir, skenario, sub-sub DAS Keyang-Slahung-Tempuran, SWAT, tata guna lahan

\begin{abstract}
Land-use change impacts the peak of flood discharge on a watershed. Every year, Ponorogo was hit by a flood during the rainy season. This research aims to analyze the impact of land-use change to the peak of flood discharge in sub-sub watersheds Keyang-Slahung-Tempuran using SWAT (Soil and Water Assessment Tool). The result shows that land-use change has an impact on increasing the peak of flood discharge. The highest peak of flood discharge occurred on March 12, 2018, with a forest cover $29.55 \%$ (land-use in 2015) has a peak of flood discharge $573.70 \mathrm{~m}^{3} / \mathrm{s}$. At the same time and use of the same rainfall data, the lowest peak of flood discharge occurred when $31.07 \%$ of forest cover (land-use in 1990) was $572.50 \mathrm{~m}^{3} / \mathrm{s}$. Based on the existing condition of land-use, floods are still occurring so a land-use scenario is needed. Scenario three is the optimal land-use, with a forest cover $45.37 \%$ obtained a peak of flood discharge $563.50 \mathrm{~m}^{3} / \mathrm{s}$ (normal alert).
\end{abstract}

Keywords: peak of flood, scenario, sub-sub watersheds of Keyang-Slahung-Tempuran, SWAT, land-use

Analisis Perubahan Tata Guna Lahan Terhadap Debit Banjir Sub-Sub Das KeyangSlahung-Tempuran (KST) - M. Khuzaimy Rurroziq Basthoni, Gusfan Halik, Entin Hidayah 


\section{Latar Belakang}

DAS merupakan suatu megasistem kompleks yang dibangun atas sistem fisik (physical systems), sistem biologis (biological systems) dan sistem manusia (human systems). Keseimbangan ekosistem akan terjamin apabila kondisi hubungan timbal balik antar komponen berjalan dengan baik dan optimal (Kartodihardjo, 2008). Vegetasi mempunyai pengaruh penting dalam besarnya retensi, baik dari segi intersepsi maupun transpirasi (Thakur, Khanal, \& Poudyal, 2017). Merencanakan, mempelajari, membangun dan mengelola daerah resapan air dilakukan untuk pelestarian air limpasan (Armon \& Hanninen, 2016).

Tata guna lahan dan penutupan lahan memiliki peran penting dalam keseimbangan ekosistem DAS (WWF, 2012; Thakur, 2015). Penggunaan lahan dan perubahan iklim mempunyai pengaruh penting dalam siklus hidrologi (Lyu, Wang, Sun, Ren, \& Zheng, 2019). Perubahan tata guna lahan karena peningkatan populasi mempengaruhi karakteristik hidrologi DAS (Mubarok et al., 2015). Analisa yang paling mudah untuk menggambarkan kondisi DAS yang kompleks adalah dengan memodelkannya (Harifa, Sholichin, \& Prayogo, 2017).

Banjir sering terjadi di Kota Ponorogo setiap tahunya, dan menyebabkan kerugian yang besar di berbagai bidang. Penggunaan lahan yang kurang bijaksana akan menyebabkan kerusakan DAS, berupa terganggunya fungsi hidrologi yang mengakibatkan terjadinya banjir (Chu et al., 2013; Mahmoud \& Alazba, 2015). Dengan memperhatikan kondisi sosial, diharapkan mampu mengurangi permasalahan penggunaan lahan pada DAS (Abbas et al., 2015). Penelitian ini membahas pengaruh perubahan tata guna serta pola tata guna lahan yang optimal terhadap puncak debit banjir. Pemodelan debit banjir dilakukan dengan menggunakan program bantu SWAT (Soil and Water Assessment Tool) berupa model hidrologi skala DAS berbasis fisik, deterministik, dan kontinyu, yang dikembangkan oleh USDA Agricultural Research Service (Arnold dkk., 1998). SWAT merupakan model semi-distributed permukaan air yang digunakan di berbagai wilayah dunia (Zomorodian \& Dowlatabadi, 2019). Beberapa makalah terbaru pemodelan hidrologi SWAT menunjukan efisiensi penerapanya di wilayah hutan hujan Brazil (Cecilo, Pimentel, \& Zanetti, 2019).

\section{Metode Penelitian}

Penelitian dilakukan bulan Juli hingga Desember 2019 di sub-sub DAS Keyang-Slahung-Tempuran yang dibatasi oleh outlet Stasiun Pengamat Arus Sungai (SPAS) Sekayu (Gambar 1). Sub-sub DAS Keyang-Slahung-Tempuran berada pada $7^{\circ} 48^{\prime} 14,1^{\prime \prime}-8^{\circ} 05^{\prime}$ 04,3" LS dan $111^{\circ} 10^{\prime} 12,6^{\prime \prime}-111^{\circ} 45^{\prime} 11,3$ " BT. Beberapa kabupaten di Provinsi Jawa Timur yang menjadi bagian dari sub-sub DAS Keyang-Slahung-Tempuran ini, yaitu Kabupaten Ponorogo, Madiun, Magetan, Trenggalek, dan Pacitan serta satu Kabupaten di Provinsi Jawa Tengah, yaitu Kabupaten Wonogiri. Bahan penelitian adalah data sekunder yang didapatkan dari beberapa instansi pemerintah meliputi: 1) Peta DEM dengan skala 1:25000; 2) Peta Tata Guna Lahan tahun 1990, 2000, 2006, dan 2015; 3) Peta Jenis Tanah; 4) Peta kemiringan Lereng; 5) Data curah hujan tahun 2009-2018; 6) Data AWLR; 7) Data iklim tahun 2009-2018. Pengolahan data spasial dan nonspasial menggunakan perangkat lunak dan software interface yaitu ArcGIS 10.3.1, ArcSWAT 2012.10.3.19., dan Microsoft Office 2018. 


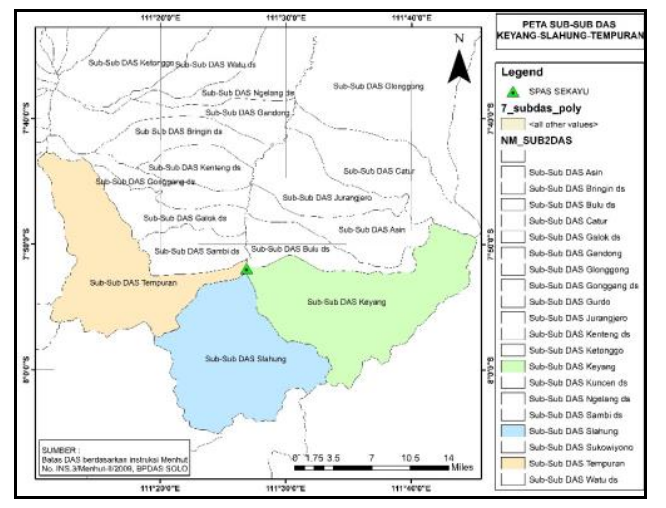

Gambar 1 Lokasi DAS Keyang-Slahung-Tempuran

Penelitian dilakukan dalam empat tahapan, tahapan pertama adalah pengumpulan data sekunder. Data ini digunakan sebagai pembuatan database untuk input ke dalam Arc-SWAT. Tahapan kedua yaitu pengolahan data hidrologi. Tahapan ketiga adalah menjalankan simulasi model menggunakan Arc-SWAT dengan beberapa tahapan pengolahan, yaitu: 1) Deliniasi DAS; 2) Pembentukan HRU (Hydrology Respones Unit); 3) Input data hidrologi dan iklim; 4) Running model SWAT; 5) Kalibrasi dan Validasi; 6) Simulasi parameter hidrologi SWAT. Tahapan keempat yaitu analisis data yang dihasilkan oleh SWAT.

Metode statistik yang digunakan untuk melakukan kalibrasi dan validasi adalah NashSutcliffe Efficiency (NSE). Nilai NSE dirumuskan sebagai berikut :

$$
N S E=1-\frac{\sum_{t=1}^{T}\left(Q_{m}^{t}-Q_{o}^{t}\right)^{2}}{\sum_{t=1}^{T}\left(Q_{o}^{t}-\bar{Q}_{o}\right)^{2}}
$$

Dengan $\mathrm{Q}_{\mathrm{m}}^{\mathrm{t}}$ adalah data observasi, $\mathrm{Q}_{\mathrm{o}}^{\mathrm{t}}$ adalah data observasi rata-rata, dan $\mathrm{Q}^{-}$o adalah data observasi rata-rata. Nilai $N S E \geq 0.5$ model $S W A T$ bisa digunakan (Silva et al., 2015). Sedangkan indikator keandalan model diukur menggunakan seperti yang ditunjukan pada Tabel 1 .

Tabel 1 Indikator keandalan model

\begin{tabular}{ccc}
\hline No & Nilai $N$ SE & Kategori \\
\hline 1 & $0.75 \leq N S E \leq 1.00$ & Sangat Baik \\
\hline 2 & $0.65 \leq N S E \leq 0.75$ & Baik \\
\hline 3 & $0.50 \leq N S E \leq 0.65$ & Memuaskan \\
\hline 4 & $N S E \leq 0.50$ & Tidak Memuaskan \\
\hline
\end{tabular}

Data debit observasi yang digunakan sebagai kalibrasi adalah data debit harian tahun 2016, sedangkan validasi menggunakan data debit harian tahun 2009, 2010, 2015, 2016, 2017, dan 2018 dari titik outlet SPAS Sungai Sekayu. Jika kalibrasi sudah dilakukan, maka selanjutnya melakukan tahap validasi. Setelah validasi dapat diterima, kemudian mensimulasikan menggunakan tata guna lahan tahun 1990, 2000, 2006, dan 2015 dengan curah hujan, iklim, dan parameter-parameter yang sama pada tahap simulasi kalibrasi dan validasi. Apabila hasil simulasi tata guna lahan existing masih belum optimal terhadap puncak debit banjir, maka dilakukan simulasi skenario pola tata guna lahan yang optimal.

Analisis Perubahan Tata Guna Lahan Terhadap Debit Banjir Sub-Sub Das KeyangSlahung-Tempuran (KST) - M. Khuzaimy Rurroziq Basthoni, Gusfan Halik, Entin Hidayah 


\section{Hasil dan Pembahasan}

\subsection{Pengolahan Data Hidrologi}

Data hidrologi, dalam hal ini adalah data curah hujan, perlu dilakukan pengolahan terlebih dahulu sebelum dimasukan kedalam Arc-SWAT. Pengolahan data hidrologi (curah hujan) dilakukan dengan dua tahapan, yaitu : 1) Perbaikan data curah hujan yang hilang, 2) Pengujian kualitas/konsistensi data curah hujan.

Terdapat delapan belas stasiun hujan yang tersebar di sub-sub DAS KeyangSlahung-Tempuran. Pada penelitian ini, semua stasiun hujan tidak dilakukan perbaikan data curah hujan yang hilang karena data curah hujan dari tahun 2009 2018 masih lengkap. Oleh karena itu pengolahan data hidrologi dilanjutkan dengan pengujian kualitas/konsistensi data curah hujan. Pengujian kualitas/ konsistensi data curah hujan perlu dilakukan agar ketelitian data yang dipakai sesuai dengan kondisi di lapangan, sehingga kesalahan data dapat ditekan. Pengujian ini menggunakan metode double mass curve dan dikatakan konsisten jika nilai $R^{2}$ mendekati nilai 1. Berdasarkan hasil pengujian kualitas/konsistensi data curah hujan didapatkan hasil konsisten pada semua stasiun hujan. Hasil pengujian kualitas/konsistensi data curah hujan dapat dilihat pada Tabel 2.

Tabel 2 Hasil pengujian kualitas/konsistensi data curah hujan

\begin{tabular}{clcc}
\hline No & \multicolumn{1}{c}{ Nama Stasiun Hujan } & $\boldsymbol{R}^{\mathbf{2}}$ & Keterangan \\
\hline 1 & Ngrayun & 0.9985 & Konsisten \\
\hline 2 & Pudak & 0.9990 & Konsisten \\
\hline 3 & Sungkur & 0.9991 & Konsisten \\
\hline 4 & Purwantoro & 0.9975 & Konsisten \\
\hline 5 & Babadan & 0.9974 & Konsisten \\
\hline 6 & Bollu & 0.9990 & Konsisten \\
\hline 7 & Talun & 0.9968 & Konsisten \\
\hline 8 & Pulung & 0.9993 & Konsisten \\
\hline 9 & Ponorogo & 0.9997 & Konsisten \\
\hline 10 & Sumorobangun & 0.9998 & Konsisten \\
\hline 11 & Slahung & 0.9991 & Konsisten \\
\hline 12 & Wilangan & 0.9991 & Konsisten \\
\hline 13 & Sooko & 0.9985 & Konsisten \\
\hline 14 & Sawoo & 0.9978 & Konsisten \\
\hline 15 & Ngilo-Ilo & 0.9985 & Konsisten \\
\hline 16 & Balong & 0.9971 & Konsisten \\
\hline 17 & Sumoroto & 0.9975 & Konsisten \\
\hline 18 & Pohijo & 0.9984 & Konsisten \\
\hline
\end{tabular}

\subsection{Deliniasi DAS}

Deliniasi batas DAS pada program Arc-SWAT dilakukan secara otomatis dengan cara memasukan peta DEM (Gambar 2) yang diproyeksikan terlebih dahulu kedalam koordinat UTM Indonesia 49S Datum WGS 1984 dan menentukan titik outlet pada DAS sebagai acuan deliniasi. Hasil pengolahan delineasi DAS Keyang-Slahung-Tempuran dapat dilihat pada Gambar 3.

Analisis Perubahan Tata Guna Lahan Terhadap Debit Banjir Sub-Sub Das KeyangSlahung-Tempuran (KST) - M. Khuzaimy Rurroziq Basthoni, Gusfan Halik, Entin Hidayah 


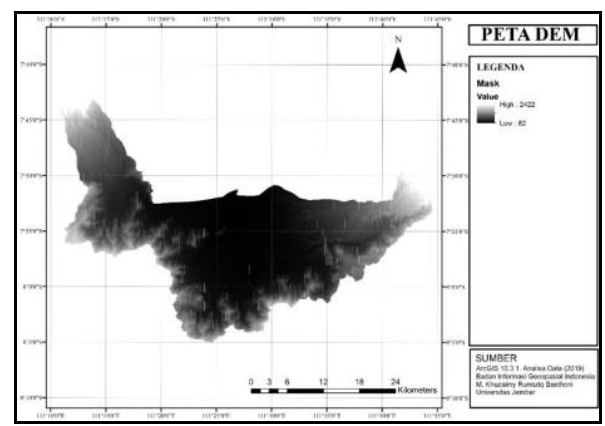

Gambar 2 Peta DEM

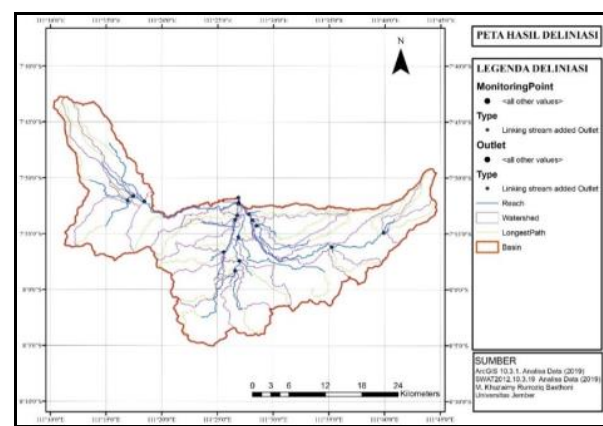

Gambar 3 Peta deliniasi

\subsection{Pembentukan $H R U$}

Pembentukan HRU (Hidrologic Respone Unit) dilakukan setelah terbentuknya deliniasi batas DAS dengan cara memasukan tiga jenis data dan melakukan threshold yaitu peta jenis tanah 20\% (Gambar 5), peta tata guna lahan 10\% (Gambar 4), dan kemiringan lereng 20\% (Gambar 6).

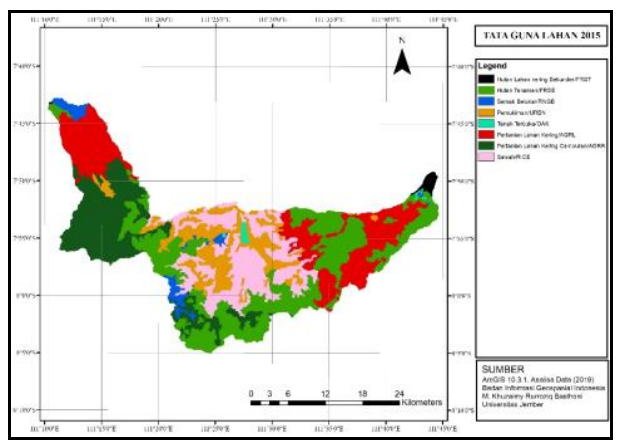

Gambar 4 Tata guna lahan

Peta jenis tanah dan peta tata guna lahan dapat dimasukan kedalam ArcSWAT apabila sudah berbentuk data raster. Pengisian kemiringan lereng, disesuaikan dengan jumlah klasifikasi kemiringan lereng sub-sub DAS KeyangSlahung-Tempuran. Pembentukan $H R U$ menghasilkan 33 Sub-basin. Hasil pengolahan $H R U$ DAS Keyang-Slahung-Tempuran dapat dilihat pada Gambar 7.

Berdasarkan hasil pengolahan data peta jenis tanah dari $F A O$, terdapat lima klasifikasi jenis tanah yang berada di sub-sub DAS Keyang-Slahung-Tempuran dan dominan dari jenis tanah I-Lc-3b-4510 dengan presentase sebanyak 36.89\%. Klasifiksai jenis tanah sub-sub DAS Keyang-Slahung-Tempuran dapat dilihat secara lengkap pada Tabel 3.

Analisis Perubahan Tata Guna Lahan Terhadap Debit Banjir Sub-Sub Das KeyangSlahung-Tempuran (KST) - M. Khuzaimy Rurroziq Basthoni, Gusfan Halik, Entin Hidayah 
Tabel 3 Jenis tanah sub-sub DAS Keyang-Slahung-Tempuran

\begin{tabular}{cccc}
\hline \multirow{2}{*}{ No } & \multirow{2}{*}{ Soilclass } & \multicolumn{2}{c}{ Luas } \\
\cline { 3 - 4 } & & ha & \% \\
\hline 1 & Tm23-2c-4573 & 4701.04 & 4.93391 \\
\hline 2 & Lv5-3b-4538 & 17212.5 & 18.0651 \\
\hline 3 & To25-2b-4576 & 13934.3 & 14.6245 \\
\hline 4 & I-Lc-3b-4510 & 35145.8 & 36.8867 \\
\hline 5 & Je62-2-3a-4518 & 24286.7 & 25.4897 \\
\hline \multicolumn{2}{c}{ Total } & 95280.3 & 100 \\
\hline
\end{tabular}

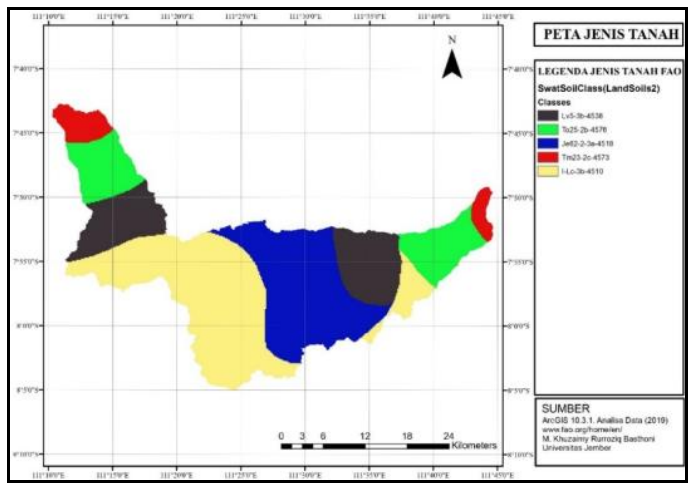

Gambar 5 Peta Jenis Tanah FAO

Peta kemiringan lereng (Gambar 6) pada penelitian ini di dapat dari PSDA Bengawan Solo dan mengklasifikasikan peta sub-sub DAS Keyang-SlahungTempuran menjadi lima tingkat kemiringan lereng. Tingkat kemiringan lereng dapat dilihat secara lengkap pada Tabel 4.

Tabel 4 Kemiringan lereng sub-sub DAS Keyang-Slahung-Tempuran

\begin{tabular}{cccc}
\hline \multirow{2}{*}{ No } & \multirow{2}{*}{ Slope $\%$} & ha & Luas \\
\cline { 3 - 4 } & $0-8$ & 24260.98 & 25.4628 \\
\hline 1 & $8-15$ & 16655.40 & 17.4804 \\
\hline 2 & $15-25$ & 15137.72 & 15.8876 \\
\hline 3 & $25-40$ & 21240.52 & 22.2927 \\
\hline 4 & $40>$ & 17985.66 & 18.8766 \\
\hline 5 & Total & 95280.27 & 100 \\
\hline
\end{tabular}

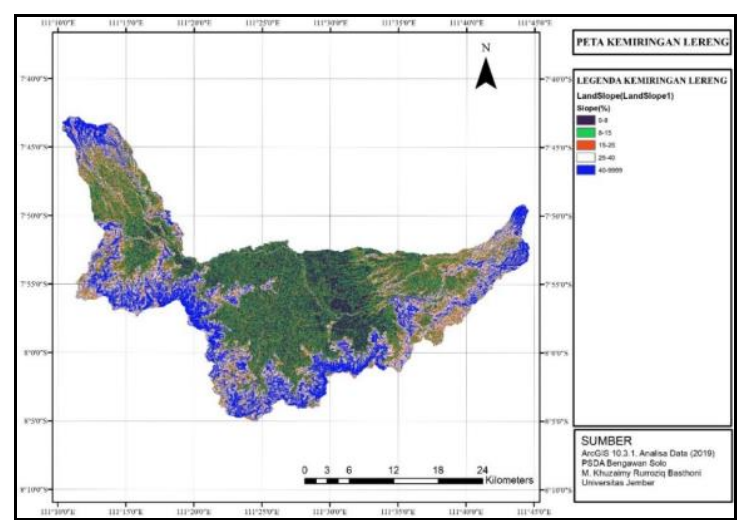

Gambar 6 Peta kemiringan lereng

Analisis Perubahan Tata Guna Lahan Terhadap Debit Banjir Sub-Sub Das KeyangSlahung-Tempuran (KST) - M. Khuzaimy Rurroziq Basthoni, Gusfan Halik, Entin Hidayah 


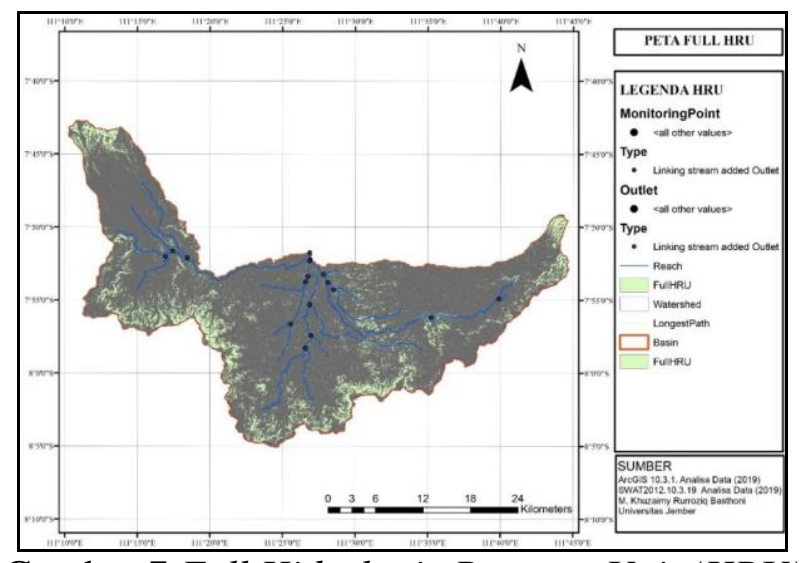

Gambar 7 Full Hidrologic Respone Unit (HRU)

\subsection{Input Data Hidrologi dan Iklim}

Untuk memproses sebuah data di dalam Arc-SWAT membutuhkan pengisian data iklim dan hidrologi agar pemodelan bisa dijalankan pada tahap selanjutnya. Di dalam penelitian ini, data iklim di isi dengan pilihan "WGEN USER". Tahap selanjutnya memasukan data curah hujan yang telah diolah menggunakan metode polygon thiessen (Gambar 8) dan dijadikan ke dalam format *.txt, serta memasukan data iklim yang telah di jadikan kedalam format *.txt.

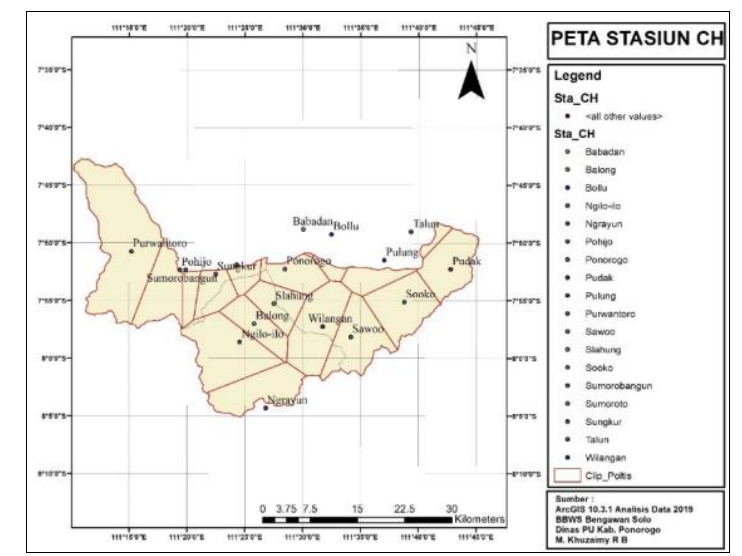

Gambar 8 Peta polygon thissen stasiun hujan

\subsection{Kalibrasi dan Validasi}

Tahap Kalibrasi dilakukan untuk menguji keandalan model, sehingga keluaran model dapat mendekati kondisi sebenarnya pada daerah penelitian yang sedang diuji. Validasi merupakan tahapan yang dilakukan setelah kalibrasi memenuhi. Validasi bertujuan untuk mengevaluasi model, guna menilai tingkat keakuratan dan konsistensi yang dimiliki suatu model untuk melakukan simulasi.

Kalibrasi dilakukan secara manual (trial and error) untuk menentukan parameter yang sesuai, dan membandingkan debit harian data model dengan debit harian data observasi yang ada pada SPAS Sekayu. Parameter pada tahap kalibrasi ditunjukan pada Tabel 5. Penentuan parameter berdasar pada Arnold et al., (2012). 
Tabel 5 Parameter model tahap kalibrasi

\begin{tabular}{|c|c|c|c|c|}
\hline No & Parameter & Keterangan & Range & Fitted Value \\
\hline 1 & CN2.mgt_R & Bilangan Kurva Aliran Permukaan & $25-98$ & 97.2 \\
\hline 2 & ESCO.hru_V & Faktor Evaporasi Tanah & $0-1$ & 1 \\
\hline 3 & SOLAWC.sol_V & Kapasitas Menahan Air & $0.5-1$ & -0.04 \\
\hline 4 & $G W Q M N \cdot g w_{-} V$ & $\begin{array}{l}\text { Batas Kedalaman Air Minimum Pada } \\
\text { Aquifer Dangkal yang Dibutuhkan } \\
\text { Untuk Kembali Terjadinya Aliran }\end{array}$ & $0-5000$ & 750 \\
\hline 5 & $G W_{-} R E V A P . g w_{-} V$ & Koefisien Penguapan Air Tanah & $0-0.2$ & 0 \\
\hline 6 & $R E V A M P M . g w_{-} V$ & Perkolasi Ke Aquifer & $0-1000$ & 1000 \\
\hline
\end{tabular}

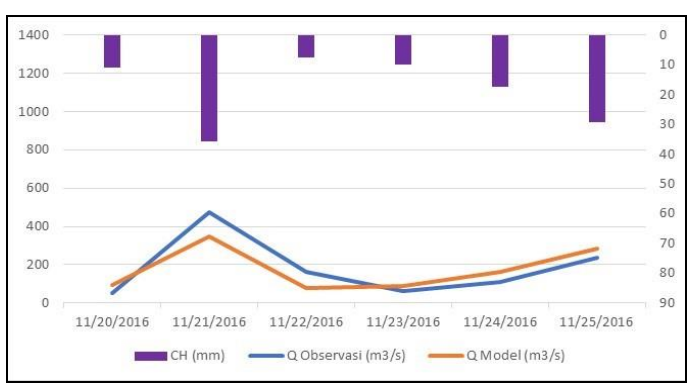

Gambar 9 Grafik kalibrasi

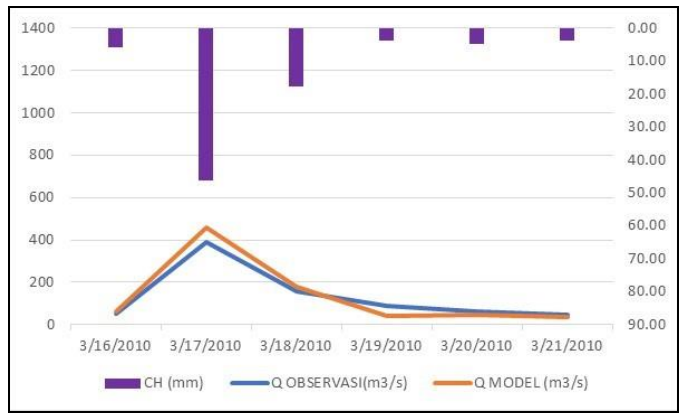

Gambar 11 Grafik validasi tahun 2010

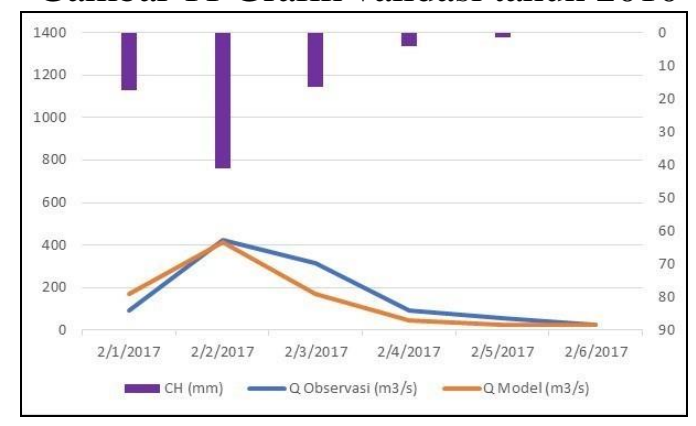

Gambar 13 Grafik validasi tahun 2017

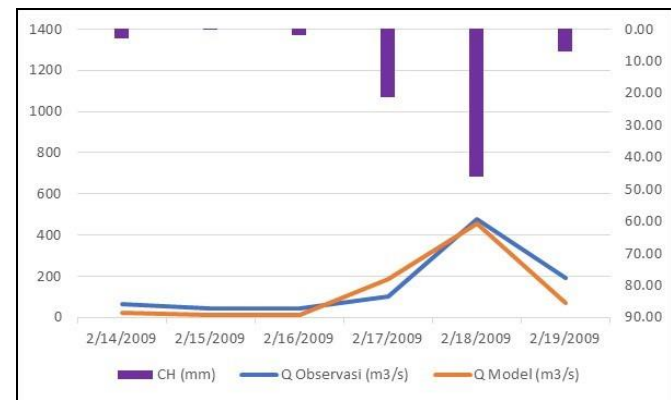

Gambar 10 Grafik validasi tahun 2009

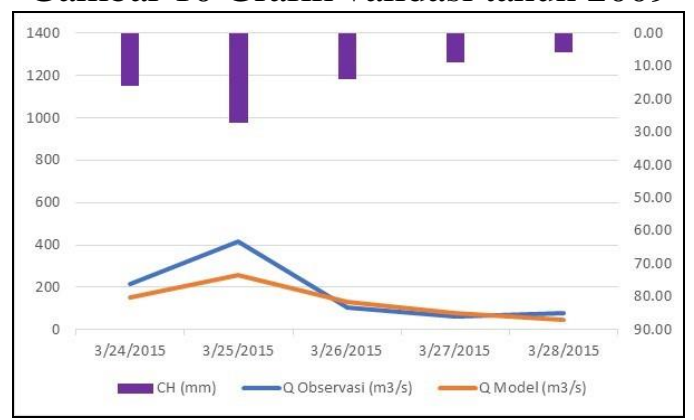

Gambar 12 Grafik validasi tahun 2015

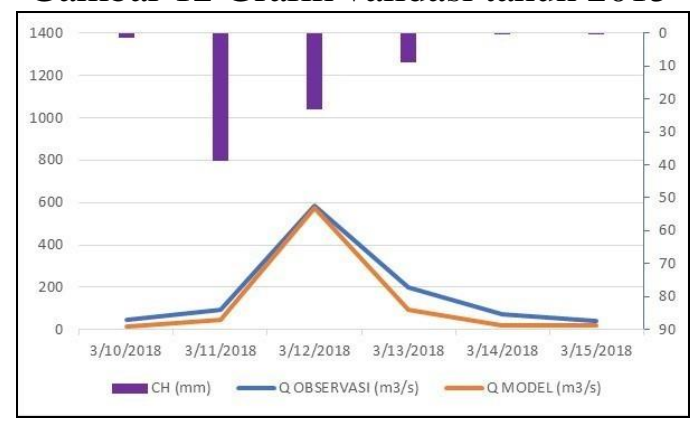

Gambar 14 Grafik validasi tahun 2018

Pada grafik Gambar 9 - 14 menunjukan puncak debit banjir tertinggi terjadi dalam waktu yang bersamaan dengan curah hujan tinggi. Dari hasil grafik kalibrasi (Gambar 9) menunjukan puncak debit banjir harian model masih dibawah dari puncak debit banjir harian observasi namun berdasarkan nilai keandalan model (NSE) menghasilkan nilai 0.751 sehingga model kalibrasi dapat diterima. Dari hasil validasi menunjukan sebagian besar puncak debit banjir harian model berada di bawah puncak debit banjir harian observasi dengan selisih

Analisis Perubahan Tata Guna Lahan Terhadap Debit Banjir Sub-Sub Das KeyangSlahung-Tempuran (KST) - M. Khuzaimy Rurroziq Basthoni, Gusfan Halik, Entin Hidayah 
nilai yang kecil (Gambar 10, 12,13, dan 14). Sedangkan pada tahun 2010 (Gambar 11) puncak debit banjir harian model berada di atas puncak debit banjir harian observasi. Hasil nilai kalibrasi dan validasi dapat dilihat secara lengkap pada Tabel 6.

Tabel 6 Hasil nilai kalibrasi dan validasi

\begin{tabular}{ccccc}
\hline No & Keterangan & Tahun & NSE & Kategori \\
\hline 1 & Kalibrasi & 2016 & 0.751 & Sangat Baik \\
2 & Validasi & 2009 & 0.812 & Sangat Baik \\
3 & Validasi & 2010 & 0.916 & Sangat Baik \\
4 & Validasi & 2015 & 0.666 & Baik \\
5 & Validasi & 2017 & 0.765 & Sangat Baik \\
6 & Validasi & 2018 & 0.922 & Sangat Baik \\
\hline
\end{tabular}

\subsection{Analisis Model Tata Guna Lahan Terhadap Puncak Debit Banjir}

Analisis model tata guna lahan bertujuan untuk mengetahui respon perubahan puncak debit banjir harian (mengalami kenaikan atau penurunan) terhadap perubahan tata guna lahan (terutama pada tata guna lahan hutan FRSE dan hutan FRST) di sub-sub DAS Keyang-Slahung-Tempuran. Proses simulasi model tata guna lahan dilakukan pada tata guna lahan di tahun-tahun tertentu yaitu tata guna lahan tahun 1990 (Gambar 15), 2000 (Gambar 16), 2006 (Gambar 17), dan 2015 (Gambar 18). Simulasi model dilakukan dengan kondisi curah hujan dan iklim yang sama yaitu data curah hujan dan iklim dengan rentang tahun 2009-2018. Antara tahun 2009-2018 curah hujan paling lebat terjadi pada tanggal 12 Maret 2018.

Tabel 7 Perubahan tata guna lahan

\begin{tabular}{lcccc}
\hline \multirow{2}{*}{\multicolumn{1}{c}{ Klasifikasi Tata Guna Lahan }} & \multicolumn{4}{c}{ Tata Guna Lahan } \\
\cline { 2 - 5 } & $\begin{array}{c}\text { Tahun } \\
\mathbf{1 9 9 0}\end{array}$ & $\begin{array}{c}\text { Tahun } \\
\mathbf{2 0 0 0}\end{array}$ & $\begin{array}{c}\text { Tahun } \\
\mathbf{2 0 0 6}\end{array}$ & $\begin{array}{c}\text { Tahun } \\
\mathbf{2 0 1 5}\end{array}$ \\
\hline Semak Belukar/RNGB & 2.61 & 2.61 & 2.64 & 2.69 \\
\hline Tanah Terbuka/OAK & 0.00 & 0.45 & 0.37 & 0.52 \\
\hline Pertanian Lahan Kering/AGRL & 19.25 & 20.52 & 20.49 & 20.52 \\
\hline Hutan Tanaman/FRSE & 29.90 & 29.05 & 28.99 & 28.82 \\
\hline Pertanian Lahan Kering Campuran/AGRR & 20.21 & 20.21 & 17.65 & 17.64 \\
\hline Hutan Lahan kering Sekunder/FRST & 1.17 & 0.73 & 0.72 & 0.73 \\
\hline Pemukiman/URBN & 8.92 & 8.92 & 12.20 & 12.16 \\
\hline Sawah/RICE & 17.94 & 17.52 & 16.95 & 16.91 \\
\hline Jumlah & 100 & 100 & 100 & 100 \\
\hline
\end{tabular}

Dari tahun 1990 hingga tahun 2015, telah terjadi banyak perubahan tata guna lahan (Tabel 7) (Gambar 15-18). Berdasarkan hasil simulasi model tata guna lahan, nilai puncak debit banjir harian mengalami peningkatan di setiap penurunan luasan hutan (FRST dan FRSE) yang terjadi (Tabel 7). Nilai puncak debit banjir harian terendah yaitu $572.50 \mathrm{~m}^{3} / \mathrm{s}$ saat luas hutan $31.07 \%$ dari total luas DAS (tata guna lahan tahun 1990). Sedangkan nilai puncak debit banjir harian tertinggi yaitu $573.70 \mathrm{~m}^{3} / \mathrm{s}$ saat luas hutan $29.55 \%$ dari total luas DAS

Analisis Perubahan Tata Guna Lahan Terhadap Debit Banjir Sub-Sub Das KeyangSlahung-Tempuran (KST) - M. Khuzaimy Rurroziq Basthoni, Gusfan Halik, Entin Hidayah 
(tata guna lahan tahun 2015). Hasil puncak debit banjir harian simulasi model dapat dilihat secara lengkap pada Tabel 8. Grafik puncak debit banjir harian dan luasan tata guna lahan hutan dapat dilihat secara lengkap pada Gambar 19. Dikarenakan debit puncak banjir harian masih melebihi ambang batas siaga hijau $\left(563,93 \mathrm{~m}^{3} / \mathrm{s}\right)$ pada tata guna lahan existing, maka diperlukan skenario pola tata guna lahan untuk menurunkan puncak debit banjir harian.

Tabel 8 Puncak debit banjir tahun tata guna lahan

\begin{tabular}{ccrr}
\hline \multirow{2}{*}{ Tata Guna Lahan } & Keterangan & Q $\left(\mathrm{m}^{3} / \mathrm{s}\right)$ & \multicolumn{1}{c}{ Luas Hutan \% } \\
\hline 1990 & Puncak Debit (Q) Model & 572.50 & 31.07 \\
\hline 2000 & Puncak Debit (Q) Model & 573.10 & 29.77 \\
\hline 2006 & Puncak Debit (Q) Model & 573.50 & 29.70 \\
\hline 2015 & Puncak Debit (Q) Model & 573.70 & 29.55 \\
\hline
\end{tabular}

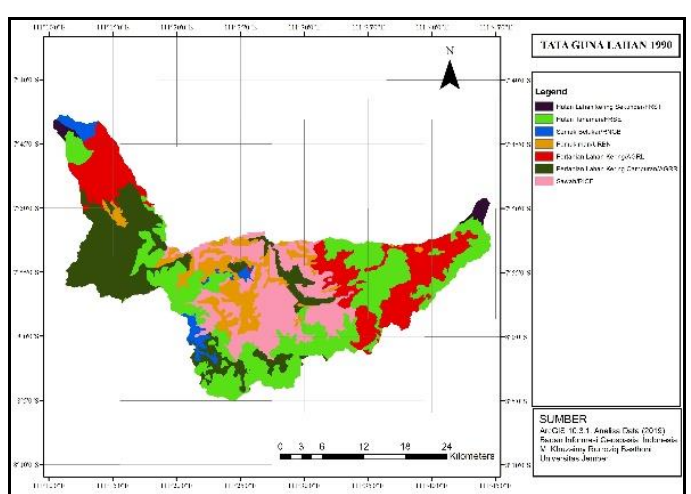

Gambar 15 Peta tata guna lahan 1990

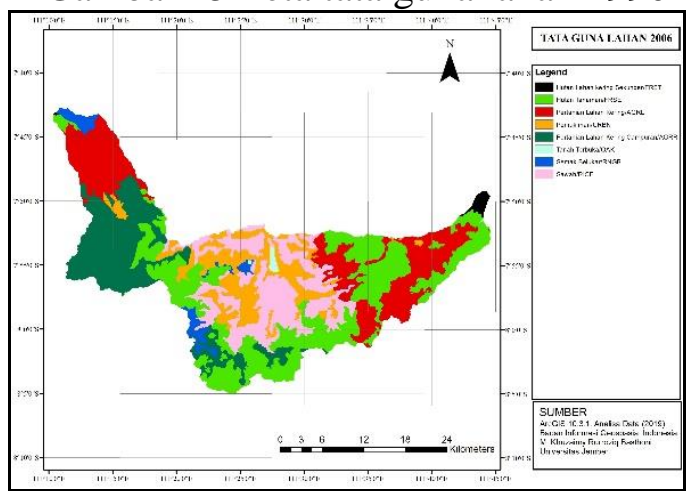

Gambar 17 Peta tata guna lahan 2006

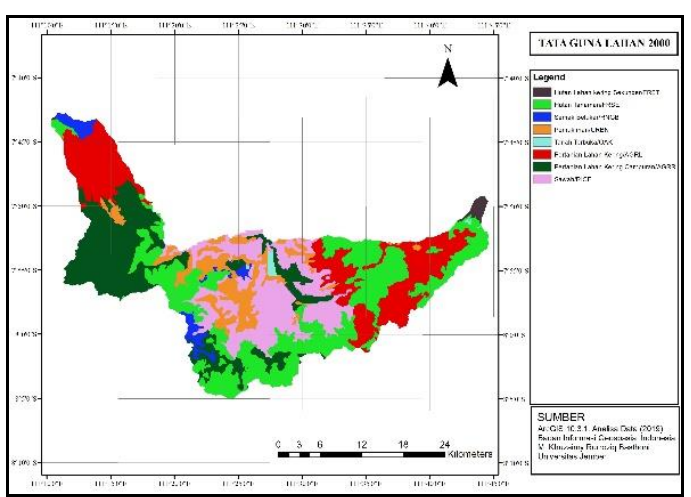

Gambar 16 Peta tata guna lahan 2000

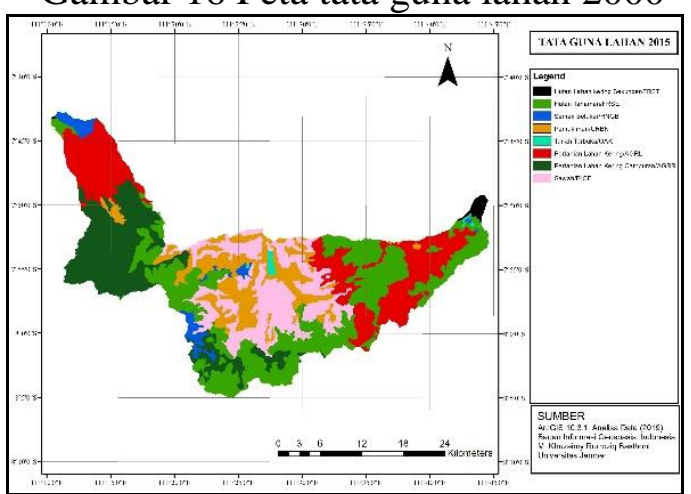

Gambar 18 Peta tata guna lahan 2015

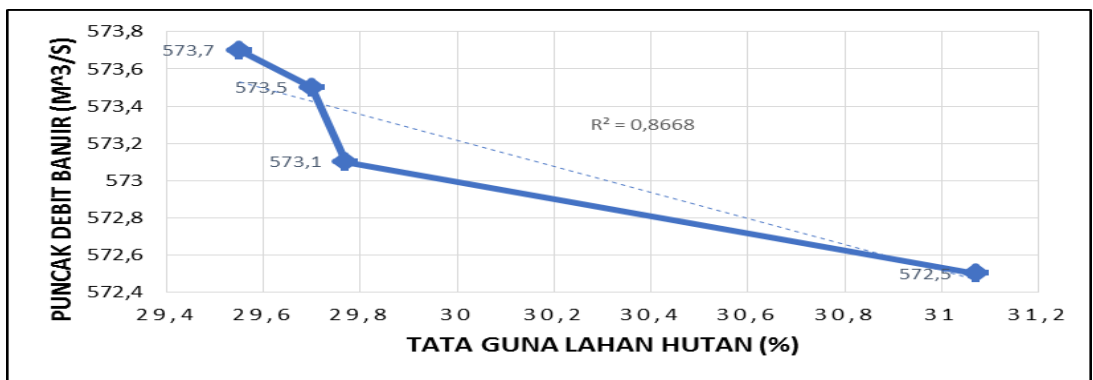

Gambar 19 Perbandingan puncak debit banjir dengan luasan tata guna lahan hutan

Analisis Perubahan Tata Guna Lahan Terhadap Debit Banjir Sub-Sub Das KeyangSlahung-Tempuran (KST) - M. Khuzaimy Rurroziq Basthoni, Gusfan Halik, Entin Hidayah 


\subsection{Analisis Pola Tata Guna Lahan Skenario Terhadap Puncak Debit Banjir}

Analisis pola tata guna lahan skenario dimaksudkan untuk mensimulasikan pola tata guna lahan agar tidak terjadi banjir. Hasil simulasi pola tata guna lahan skenario agar tidak terjadi banjir dapat dilihat dari nilai puncak debit banjir berada dibawah ambang batas siaga hijau $\left(563,93 \mathrm{~m}^{3} / \mathrm{s}\right)$ atau siaga normal. Pola tata guna lahan skenario dibuat dengan meningkatkan luasan hutan (FRST dan FRSE) di beberapa skenario dengan asumsi mengalihfungsikan beberapa jenis tata guna lahan untuk dirubah ke jenis tata guna lahan hutan (FRST dan FRSE). Terdapat tiga skenario yang dibuat, yaitu: skenario 1 (Gambar 20 dan 21), skenario 2 (Gambar 22 dan 23), dan skenario 3 (Gambar 24 dan 25). Luas hutan hutan skenario 1, 2, dan 3 masing - masing sebesar 32,83\%, 40,61\%, dan 45,37\% (Tabel 9). Puncak debit banjir hasil simulasi dapat dilihat secara lengkap pada Tabel 10 .

Tabel 9 Perubahan tata guna lahan skenario

\begin{tabular}{lccc}
\hline \multirow{2}{*}{ Klasifikasi Tata Guna Lahan } & \multicolumn{3}{c}{ Tata Guna Lahan \% } \\
\cline { 2 - 4 } & Skenario 1 & Skenario 2 & Skenario 3 \\
\hline Semak Belukar/RNGB & 0 & 0 & 0 \\
\hline Tanah Terbuka/OAK & 0 & 0 & 0 \\
\hline Pertanian Lahan Kering/AGRL & 20.51 & 12.74 & 7.98 \\
\hline Hutan Tanaman/FRSE & 32.12 & 39.90 & 44.66 \\
\hline Pertanian Lahan Kering Campuran/AGRR & 17.69 & 17.68 & 17.66 \\
\hline Hutan Lahan kering Sekunder/FRST & 0.71 & 0.71 & 0.71 \\
\hline Pemukiman/URBN & 12.11 & 12.10 & 12.04 \\
\hline Sawah/RICE Jumlah & 16.85 & 16.87 & 16.95 \\
\hline \multicolumn{2}{c}{$\quad 100$} & 100 & 100 \\
\hline
\end{tabular}

Tabel 10 Puncak debit banjir tata guna lahan skenario

\begin{tabular}{cccc}
\hline \multirow{2}{*}{ Pola Tata Guna Lahan } & Keterangan & Q $\left(\mathrm{m}^{3} / \mathrm{s}\right)$ & Luas Hutan \% \\
\hline Skenario 1 & Puncak Debit (Q) Model & 572.70 & 32.83 \\
\hline Skenario 2 & Puncak Debit (Q) Model & 564.60 & 40.61 \\
\hline Skenario 3 & Puncak Debit (Q) Model & 563.50 & 45.37 \\
\hline
\end{tabular}

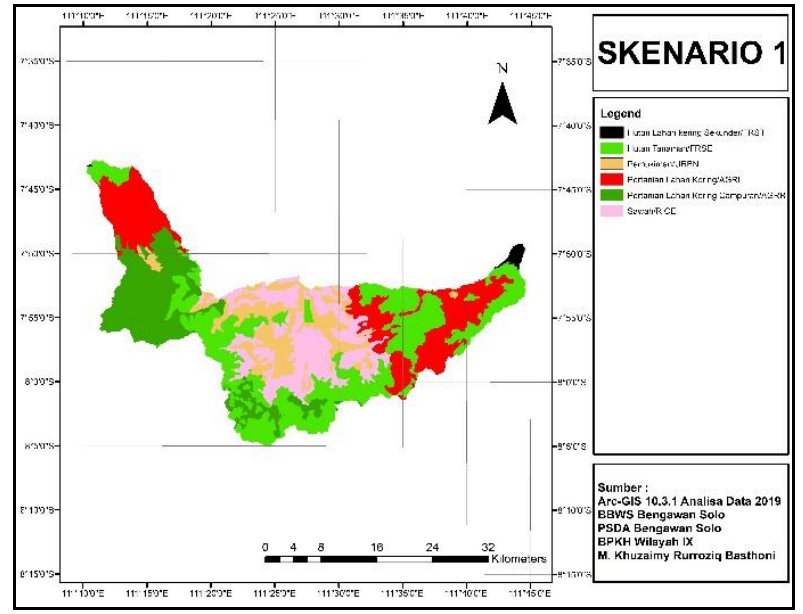

Gambar 20 Peta tata guna lahan skenario 1

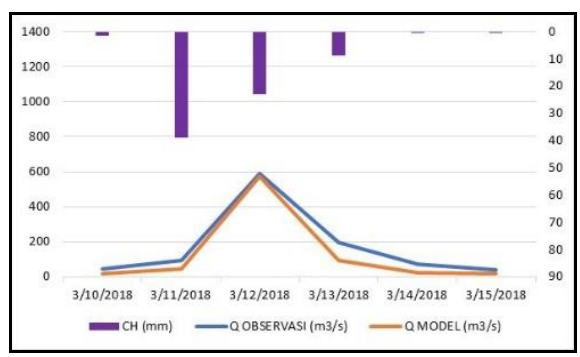

Gambar 21 Grafik puncak debit banjir skenario 1

Analisis Perubahan Tata Guna Lahan Terhadap Debit Banjir Sub-Sub Das KeyangSlahung-Tempuran (KST) - M. Khuzaimy Rurroziq Basthoni, Gusfan Halik, Entin Hidayah 


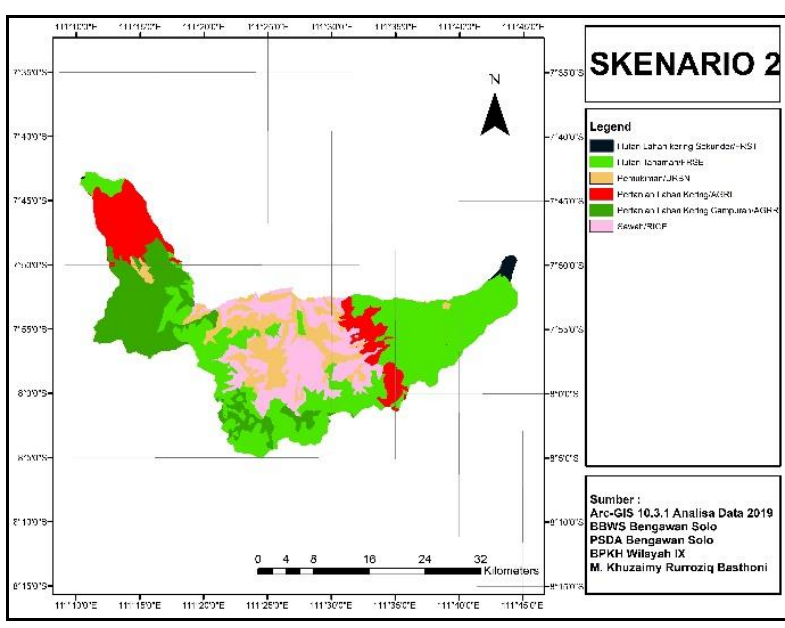

Gambar 22 Peta tata guna lahan skenario 2

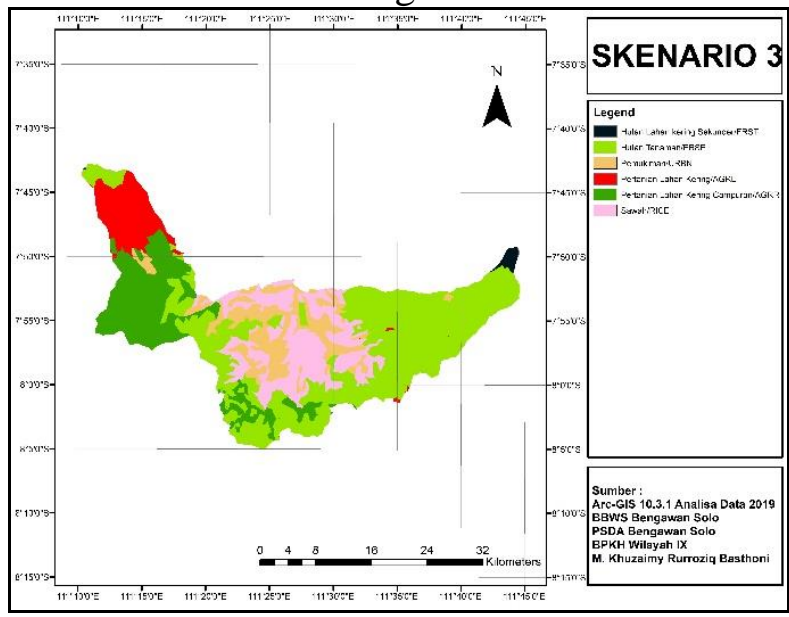

Gambar 24 Peta tata guna lahan skenario 3

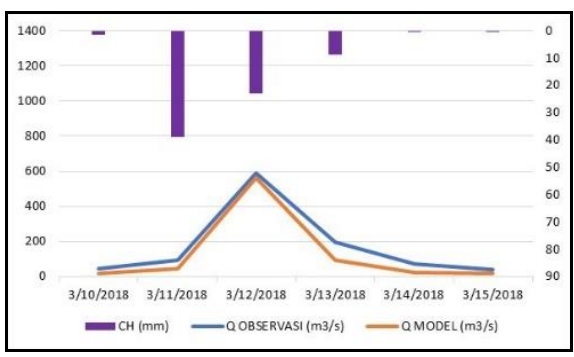

Gambar 23 Grafik puncak debit banjir skenario 2

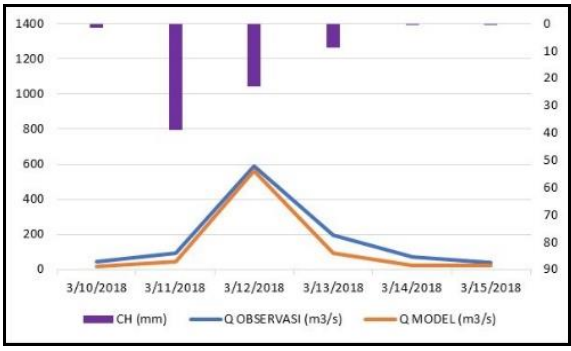

Gambar 25 Grafik puncak debit banjir skenario 3

Skenario tiga merupakan pola tata guna lahan yang optimal agar puncak debit banjir berada di bawah ambang siaga hijau. Skenario tiga memiliki luasan hutan $45.37 \%$ dari total luas DAS dan menghasilkan nilai titik puncak debit banjir yaitu $563.50 \mathrm{~m}^{3} / \mathrm{s}$, yang berarti lebih kecil dari ambang bawah siaga hijau yaitu $563.93 \mathrm{~m}^{3} / \mathrm{s}$. Perbandingan puncak debit banjir dan luasan tata guna lahan hutan skenario dapat dilihat pada Gambar 26.

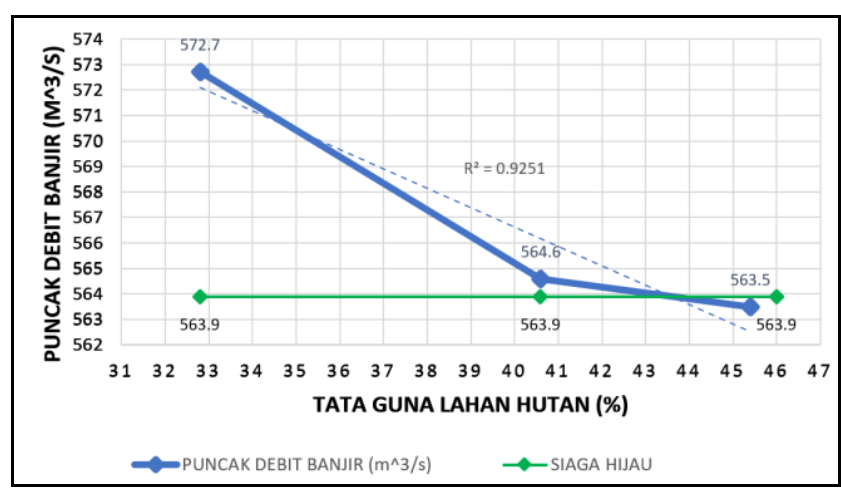

Gambar 26 Perbandingan puncak debit banjir dengan luasan tata guna lahan hutan skenario

Analisis Perubahan Tata Guna Lahan Terhadap Debit Banjir Sub-Sub Das KeyangSlahung-Tempuran (KST) - M. Khuzaimy Rurroziq Basthoni, Gusfan Halik, Entin Hidayah 


\section{Kesimpulan dan Saran}

\subsection{Kesimpulan}

Berdasarkan analisa hasil dan pembahasan, maka dapat disimpulkan beberapa hal:

1. Pemodelan hujan aliran menggunakan Arc-SWAT di sub-sub DAS KeyangSlahung-Tempuran menghasilkan nilai keandalan model sangat baik. Pada tahap kalibrasi (2016) memiliki nilai NSE sebesar 0.751. Pada tahap validasi tahun 2009, 2010, 2015, 2017, dan 2018 menghasilkan nilai NSE masingmasing sebesar $0.812,0.916,0.666,0.765,0.922$.

2. Hasil running model tata guna lahan tahun 1990, 2000, 2006, dan 2015, secara berurutan menghasilkan puncak debit banjir yaitu $572.50 \mathrm{~m}^{3} / \mathrm{s}, 573.10 \mathrm{~m}^{3} / \mathrm{s}$, $573.50 \mathrm{~m}^{3} / \mathrm{s}$, dan $573.70 \mathrm{~m}^{3} / \mathrm{s}$. Peningkatan nilai puncak debit banjir berbanding terbalik dengan penurunan luasan hutan.

3. Skenario tiga merupakan kondisi optimal pola tata guna lahan sub-sub DAS Keyang-Slahung-Tempuran supaya tidak terjadi banjir.

\subsection{Saran}

Untuk meningkatkan akurasi data hasil pemodelan dengan data di lapangan maka sebaiknya dibangun pos pencatat TMA otomatis (AWLR) disetiap outlet sub-sub DAS.

\section{Daftar Kepustakaan}

Abbas, T., Nabi, G., Boota, M. W., Hussain, F., Faisal, M., Ahsan, H. Lahore, T., 2015. Impacts of Landuse Changes on Runoff Generation in Simly. Lahore 27(4), 3185-3191.

Armon R.H., Hanninen O., 2016. Environmental indicators. Springer. ISBN 9402403825 pp. 1068.

Arnold, J.G., R. Srinivasan., Muttiah R. S., dan Williams, J.R., 1998. Large-area hydrologic modeling and assessment: Part I. Model development. J. American Water Resour. Assoc. 34(1): 73-89.

Arnold, J.G., D.N. Moriasi, P.W. Gassman, K.C. Abbaspour, M.J. White, R. Srinivasan, C. Santhi, R.D. Harmel, A.V. Griensven, M.W.V. Liew, N. Kannan, and M.K. Jha. 2012. SWAT: model use, calibration, and validation. J. American Society of Agricultural and Biological Engineers, 55: 14911508.

Cecilo, R. A., Pimentel, S. M., \& Zanetti, S. S., 2019. Catena Modeling the in fl uence of forest cover on stream fl ows by di ff erent approaches. CATENA, 178(October 2018), 49-58. https://doi.org/10.1016/j.catena.2019.03.006

Chu, H. J., Liu, C. Y., \& Wang, C. K., 2013. Identifying the relationships between water quality and land cover changes in the tseng-wen reservoir watershed of Taiwan. International Journal of Environmental Research and Public Health, 10(2), 478-489.

Harifa, A. C., Sholichin, M., \& Prayogo, T. B., 2017. Analisa Pengaruh Perubahan Penutupan Lahan Terhadap Debit Sungai Sub DAS Metro dengan Menggunakan Program ARCSWAT. Jurnal Teknik Pengairan, 8(1), $1-14$.

Analisis Perubahan Tata Guna Lahan Terhadap Debit Banjir Sub-Sub Das KeyangSlahung-Tempuran (KST) - M. Khuzaimy Rurroziq Basthoni, Gusfan Halik, Entin Hidayah 
Kartodihardjo, H., 2008. Analisis kelembagaan pengelolaan daerah aliran sungai : konsep, Paradox dan Masalah, serta Upaya Peningkatan Kinerja. Makalah Lokakarya.

Lyu, L., Wang, X., Sun, C., Ren, T., \& Zheng, D., 2019. Quantifying the Effect of Land Use Change and Climate Variability on Green Water Resources in the Xihe River Basin , Northeast China. Sustainability, 11(2), 338. https://doi.org/10.3390/su11020338

Mahmoud, S. H., \& Alazba, A. A., 2015. Hydrological response to land cover changes and human activities in arid regions using a geographic information system and remote sensing. PLoS ONE, 10(4), 1-20.

Mubarok, Z., K. Murtilaksosno, dan E. D. Wahjunie., 2015. Study of land use change response to the hirological characteristics of Way Betung - Lampung watershed. Journal of Wallacea Forestry Research. 4(1). pp. $1-10$.

Silva, G.M., A.A.O. Netto, J.J.R. Neves, N.A. Vasco, C. Ahmeida and G.G. Faccioli. 2015. Sensitivity analysis and calibration of hydrological modeling of the watershed Northeast Brazil. Journal of Environmental Protection. Campus São Cristóvão, Brazil.

Thakur, J. K., 2015. Optimizing groundwater monitoring networks using integrated statistical and geostatistical approaches. Hydrology 2 (3), 148175.

Thakur, J. K., Khanal, K., \& Poudyal, K., 2017. Land cover changes for enhancing water availability in watersheds of Tanahun and Kaski, Nepal. Journal of Water and Climate Change, 10(2)(October), 431-448. https://doi.org/10.2166/wcc.2017.001

WWF., 2012. Water Poverty of Indravati Basin, Analysis and Mapping. WWF, Nepal.

Zomorodian, S. M. A., \& Dowlatabadi, S. 2019. Modeling of river discharge in the Firoozabad watershed using soil and water assessment tool model. International Journal of Energy and Water Resources, 3(0123456789), 1321. https://doi.org/10.1007/s42108-018-0007-y.

Copyright (c) M. Khuzaimy Rurroziq Basthoni

Analisis Perubahan Tata Guna Lahan Terhadap Debit Banjir Sub-Sub Das KeyangSlahung-Tempuran (KST) - M. Khuzaimy Rurroziq Basthoni, Gusfan Halik, Entin Hidayah 